調査・資料

\title{
ワイン，魚介類，精米，乳，粉乳およびヨーグルト中の 過塩素酸塩濃度の実態調査
}

(平成 22 年 7 月 20 日受理)

\author{
高 附 巧* 渡邉敬浩＼cjkstart松田りえ子
}

Surveillance of Perchlorate Level in Wine, Seafood, Polished Rice, Milk, Powdered Milk and Yogurt

Satoshi Takatsuki*, Takahiro Watanabe and Rieko Matsuda

National Institute of Health Sciences: 1-18-1 Kamiyoga, Setagaya-ku, Tokyo 158-8501, Japan; ${ }^{*}$ Corresponding author

Perchlorate, which may be naturally occurring or artificial in origin, inhibits iodide uptake into the thyroid gland and disturbs thyroid function. In order to investigate perchlorate contamination in foods in Japan, perchlorate levels in 28 wine samples, 20 seafood samples, 10 polished rice samples, 30 milk (include whole milk, composition modified milk, low fat milk, processed milk, milk drink) samples, 10 powdered milk samples and 10 yogurt samples were measured. Perchlorate was found in all wine, milk, powdered milk and yogurt samples tested. Perchlorate levels ranged from $0.2 \mathrm{ng} / \mathrm{g}$ to $103 \mathrm{ng} / \mathrm{g}$ in wine samples, from $2 \mathrm{ng} / \mathrm{g}$ to $11 \mathrm{ng} / \mathrm{g}$ in milk samples, from $3 \mathrm{ng} / \mathrm{g}$ to $35 \mathrm{ng} / \mathrm{g}$ in powdered milk samples, and from $2 \mathrm{ng} / \mathrm{g}$ to $11 \mathrm{ng} / \mathrm{g}$ in yogurt samples. Perchlorate levels in the seafood samples were under the LOQ $(0.8 \mathrm{ng} / \mathrm{g})$ in $8 \mathrm{samples}$ and ranged from $0.8 \mathrm{ng} / \mathrm{g}$ to $72 \mathrm{ng} / \mathrm{g}$ in 12 samples. In all polished rice samples, perchlorate level was under the LOQ $(1.0 \mathrm{ng} / \mathrm{g})$.

(Received July 20, 2010)

Key words: 過塩素酸塩 perchlorate; イオンクロマトグラフィーータンデム質量分析法 IC-MS/MS; ワ イン wine; 魚介類 seafood; 精米 polished rice; 乳 milk; 粉乳 powdered milk; ヨーグルト yogurt

\section{緒言}

過塩素酸塩は天然に広く存在するとともに，固形ロケッ 卜燃料, 花火, 電池などに広く使用されている。過塩素酸 塩には甲状腺でのヨウ素の取り込みを阻害する作用があ り，ヨウ素欠乏状態にある女性において，過塩素酸塩暴露 と甲状腺機能低下に有意な関連があるとの報告がある ${ }^{1)}$. 米国では，国立および民間の研究機関などが野菜，果実， 飲料水, 牛乳, 魚介類などのさまざまな食品中の過塩素酸

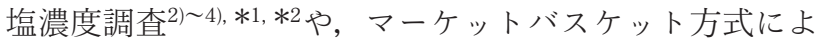
るトータルダイエットスタディー $(\mathrm{TDS}) * 1, * 3$ を実施し, それらの結果を報告している.

\footnotetext{
* 連絡先

国立医薬品食品衛生研究所：干158-8501 東京都世田谷区 上用賀 1-18-1

*1 http: / / www. fda. gov / Food / FoodSafety / Food ContaminantsAdulteration / ChemicalContaminants / Perchlorate/ucm077572.htm, 2009

*2 http: / / www. fda. gov / Food / FoodSafety / Food ContaminantsAdulteration / ChemicalContaminants / Perchlorate/ucm077685.htm, 2009
}

既報5において，わが国における食品中の過塩素酸塩濃 度の実態を把握するために，国内で市販されている葉菜を 中心とした野菜およびミネラルウォーター中の過塩素酸塩 濃度を測定し，その結果を報告した。今回，上記食品以外 で過塩素酸塩が含まれていることが報告されている6),*1,*3 ワイン, 魚介類, 乳 (牛乳, 成分調整牛乳, 低脂肪牛乳, 加工乳, 乳飲料), 粉乳, ヨーグルトおよび, 過塩素酸塩 が含まれている報告はないが主食であり摂取量の多い精米 中の過塩素酸塩濃度の実態を調査した結果を報告する.

\section{実 験 方 法}

\section{1. 試料}

2008 年 12 月から 2009 年 2 月にかけて，東京都の小 売店で販売されていた乳（牛乳 20 試料, 成分調整牛乳 1 試料, 低脂肪牛乳 3 試料, 加工乳 1 試料, 乳飲料 5 試料) 計 30 試料，魚介類 20 試料およびヨーグルト 10 試料を購

\footnotetext{
*3 http: / / www. fda. gov / Food / FoodSafety / Food ContaminantsAdulteration / ChemicalContaminants / Perchlorate/ucm077615.htm, 2009
} 
入し検体とした。また，2008 年 10 月から 12 月に国産お よび輸入ワイン計 28 試料, 2007 年 12 月に精米 10 試料 および 2008 年 12 月に粉乳 10 試料を, インターネット を通じて購入し，検体とした。

\section{2. 試薬および試液}

1) 標準品および標準溶液 過塩素酸ナトリウム, ${ }^{18} \mathrm{O}_{4}$ 標識過塩素酸ナトリウム内部標準 (IS) および標準溶液 は，既報5)に従い用いた。

2) その他試薬および試液 超純水：Mili Q 水（超純 水を用いることで IC-MS/MS のベースラインが低くなっ たので既報5の蒸留水から変更した). 酢酸, アセトニト リル，酢酸アンモニウム，1％酢酸溶液および固相抽出 カートリッジは，既報5に従った。

\section{3. 器具および器材}

マイクロシリンジ：容量 $100 \mu \mathrm{L}$ およ゙ $250 \mu \mathrm{L}$ (Hamilton 社製)。シリンジフィルター，ディスポーザブ ルシリンジ，ポリプロピレン製遠心管，フードプロセッ サーおよびカラム吸引装置は既報5) に従った。粉砕器：ミ ルサー IFM-800 (岩谷産業(株)製), 遠心分離機：ユニ バーサル冷却遠心機 5930, ローター RS-3011M（(株） 久保田製作所製), 振とう機: RECIPRO SHAKER SR$2 \mathrm{~W}$ (タイテック(株)製).

4. IC-MS/MS 装置および測定条件 IC 装置, MS/MS 装置および測定条件は既報5)に従った。

5. 試験溶液の調製 FDA がインターネット上に公表 している分析法*4および文献 7,8 を参考に以下に示すと おり，試験溶液を調製した。

\section{1) 抽出}

魚介類は, フードプロセッサーで, 精米は粉砕器で均一 になるまで粉砕した。 ワインおよび魚介類は $10.0 \mathrm{~g}$ を, 乳およびヨーグルトは $5.0 \mathrm{~g}$ を，粉乳は $1.0 \mathrm{~g}$ をポリプロ ピレン製遠心管に量り採った. $100 \mu \mathrm{L}$ シリンジを用いて, ワインおよび魚介類は, $1.5 \mu \mathrm{g} / \mathrm{mL}$ IS 溶液 $100 \mu \mathrm{L}$ を, 乳, ヨーグルトおよび粉乳は $2.0 \mu \mathrm{g} / \mathrm{mL}$ IS 溶液 $100 \mu \mathrm{L}$ を添加し, ワインは $1 \%$ 䣷酸溶液 $20 \mathrm{~mL}$ を, 魚介類は 1\%酢酸溶液 $5 \mathrm{~mL}$ およびアセトニトリル $15 \mathrm{~mL}$ を，精 米は $1 \%$ 䣷酸溶液 $20 \mathrm{~mL}$ およびアセトニトリル $20 \mathrm{~mL}$ を，乳およびヨーグルトは $1 \%$ 酢酸溶液 $5 \mathrm{~mL}$ およびアセ トニトリル $20 \mathrm{~mL}$ を, 粉乳は $1 \%$ 酢酸溶液 $10 \mathrm{~mL}$ および アセトニトリル $20 \mathrm{~mL}$ を加えた後, 密栓して 2 分間振と うした後, 毎分 2,000 回転で 5 分間遠心分離した.

\section{2）精製}

ワイン, 魚介類および精米：あらかじめアセトニトリル $6 \mathrm{~mL}$ および $1 \%$ 酶酸溶液 $6 \mathrm{~mL}$ を通し吸引により 30 秒 間乾燥させた固相抽出 (SPE) カートリッジに, 遠心後の 上清を全量注入し, 溶出液をポリプロピレン製遠心管に集 めた. SPEカートリッジからの溶出が毎秒 2 滴になるよ

*4 http: / / www. fda. gov / Food / FoodSafety / Food ContaminantsAdulteration / ChemicalContaminants / Perchlorate/ucm077793.htm, 2009
うに吸引装置の減圧率を調整した。溶出液をシリンジフィ ルターでろ過し試験溶液とした。

乳，ヨーグルトおよび粉乳：あらかじめアセトニトリル $6 \mathrm{~mL}$ および $1 \%$ 酢酸溶液 $6 \mathrm{~mL}$ を通した SPE カートリッ ジに，遠心後の上清を全量注入し，溶出液をポリプロピレ ン製遠心管に集めた．次いで，カラムに $1 \%$ 酢酸溶液 6 $\mathrm{mL}$ を注入し, 溶出液を先の容器に集めた. SPEカート リッジからの溶出が毎秒 2 滴になるように吸引装置の減 圧率を調整した。溶出液を $1 \%$ 酷酸溶液で $40 \mathrm{~mL}$ とした 後, シリンジフィルターでろ過し試験溶液とした。

\section{6. 定量}

既報5) と同様に行った。検量線は常に原点を通る直線が 得られ，決定係数 $\left(R^{2}\right)$ は 0.9999〜1.0000 であった。

\section{結果および考察}

\section{1. 分析方法の室内バリデーション}

分析を実施する試験室における方法と手順を含む一連の 分析システムの性能を評価するために，室内バリデーショ ンを実施した。

1) 操作ブランク 分析ごとに, 超純水を試料として, ブ ランク試験を実施した。操作ブランク中の過塩素酸塩濃度 は, 検量線用の $0.0 \mathrm{ng} / \mathrm{mL}$ 溶液を超えることはなかった。

\section{2) 回収率および併行精度, 室内精度の評価 ワイン,} 魚介類, 精米および牛乳について, 無添加および過塩素酸 塩を $2.0 \mathrm{ng} / \mathrm{g}, 4.0 \mathrm{ng} / \mathrm{g}$ (牛乳は $5.0 \mathrm{ng} / \mathrm{g}, 10.0 \mathrm{ng} / \mathrm{g}$ ) 添 加した試料を調製し， 1 日各 2 併行で， 5 日間， 1 人が分 析方法に従って操作した。無添加試料から得た定量結果の 平均值 $(n=10)$ は, ワイン $0.121 \mathrm{ng} / \mathrm{g}$, 魚介類 0.385 $\mathrm{ng} / \mathrm{g}$, 精米 $0.136 \mathrm{ng} / \mathrm{g}$, 牛乳 $1.949 \mathrm{ng} / \mathrm{g}$ であった。添 加試料の結果から無添加試料の平均を差し引いた值の平均 值を添加量で除して回収率を求めた。また，一元配置の分 散分析により算出された分散に基づき, 併行精度, 室内精 度を推定した。それらの結果を Table 1 に示す。いずれ の添加量でも，回収率は 90\%以上，併行精度および室内 精度は相対標準偏差 (RSD) として 7\%以下であり，実態 調査の目的に適合していると考えられた。 IC-MS/MS ク ロマトグラムの一例として, $0.1 \mathrm{ng} / \mathrm{mL}$ 標準溶液 (IS 5.0 $\mathrm{ng} / \mathrm{mL})$ および無添加ワインの試験溶液の結果を Fig. 1 に示した。

3）検出限界および定量限界 既報5) と同様に，各無添 加試料の定量結果の標準偏差の 3 倍および 10 倍をそれぞ れ検出限界 (LOD) と定量限界 (LOQ) とした。 ワインの LOD は $0.03 \mathrm{ng} / \mathrm{g}, \mathrm{LOQ}$ は $0.1 \mathrm{ng} / \mathrm{g}$, 魚介類の LOD は $0.2 \mathrm{ng} / \mathrm{g}, \mathrm{LOQ}$ は $0.8 \mathrm{ng} / \mathrm{g}$, 精米の LOD は $0.3 \mathrm{ng} / \mathrm{g}$, $\mathrm{LOQ}$ は $1.0 \mathrm{ng} / \mathrm{g}$, 牛乳の LOD は $0.1 \mathrm{ng} / \mathrm{g}, \mathrm{LOQ}$ は 0.4 $\mathrm{ng} / \mathrm{g}$ となった。ヨーグルトは牛乳と同様の方法のため, LOD および LOQ は牛乳と同一とみなした. 粉乳は試料 量が牛乳の 5 分の 1 であるため LOD および LOQ が牛乳 の 5 倍となるものと想定し, LOD は $0.7 \mathrm{ng} / \mathrm{g}, \mathrm{LOQ}$ は $2.2 \mathrm{ng} / \mathrm{g}$ とした. 
Table 1. The performance characteristics of the analytical system in the laboratory

\begin{tabular}{|c|c|c|c|c|c|c|}
\hline \multirow{2}{*}{ Foods } & \multirow{2}{*}{$\begin{array}{l}\text { Fortification level }{ }^{* 1} \\
\qquad(\mathrm{ng} / \mathrm{g})\end{array}$} & \multirow{2}{*}{$\begin{array}{c}\text { Recovery } \\
(\%)\end{array}$} & \multicolumn{2}{|c|}{ Repeatability } & \multicolumn{2}{|c|}{ Intermediate precision } \\
\hline & & & $\mathrm{SD}^{* 2}(\mathrm{ng} / \mathrm{g})$ & $\mathrm{RSD}^{* 3}(\%)$ & $\mathrm{SD}(\mathrm{ng} / \mathrm{g})$ & $\operatorname{RSD}(\%)$ \\
\hline \multirow[t]{2}{*}{ Wine } & 2.0 & 98.1 & 0.016 & 0.81 & 0.028 & 1.41 \\
\hline & 4.0 & 97.9 & 0.021 & 0.55 & 0.037 & 0.95 \\
\hline \multirow[t]{2}{*}{ Seafoods } & 2.0 & 101.3 & 0.070 & 3.46 & 0.130 & 6.49 \\
\hline & 4.0 & 101.4 & 0.130 & 3.15 & 0.140 & 3.46 \\
\hline \multirow[t]{2}{*}{ Polished rice } & 2.0 & 91.9 & 0.100 & 5.18 & 0.100 & 5.18 \\
\hline & 4.0 & 98.0 & 0.180 & 4.50 & 0.180 & 4.50 \\
\hline \multirow[t]{2}{*}{ Whole milk } & 5.0 & 99.8 & 0.036 & 0.73 & 0.100 & 2.01 \\
\hline & 10.0 & 98.4 & 0.020 & 0.21 & 0.200 & 2.03 \\
\hline
\end{tabular}

*1 Perchlorate anion level

*2 SD: Standard deviation

*3 RSD: Relative standard deviation
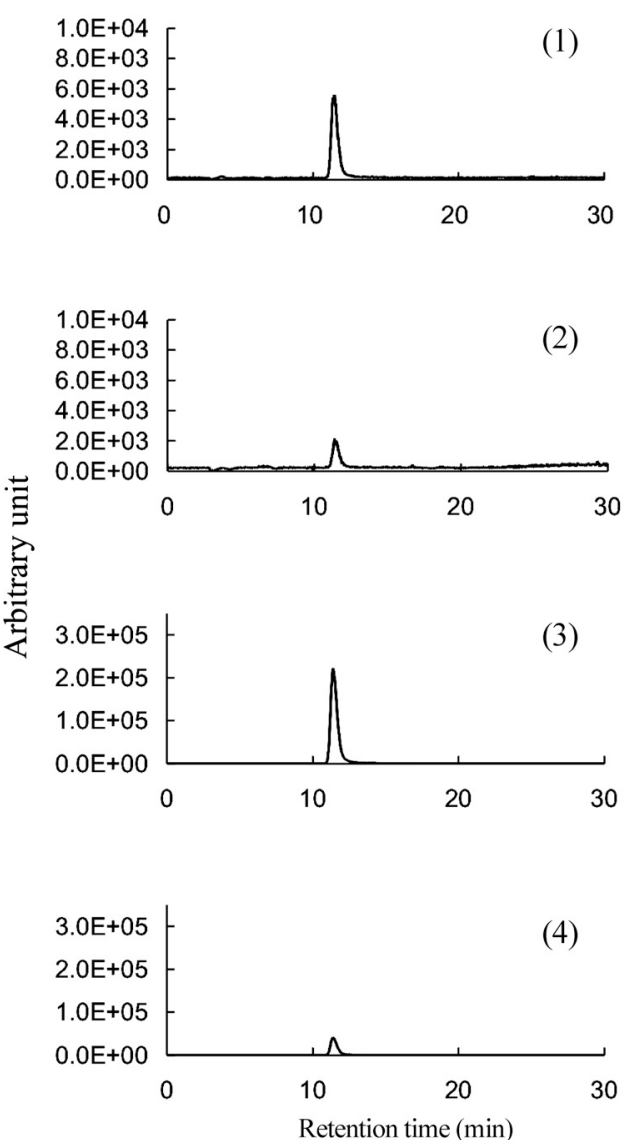

B

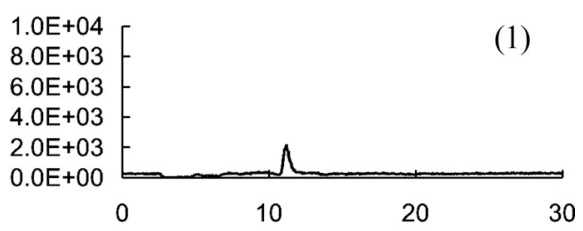

(2)
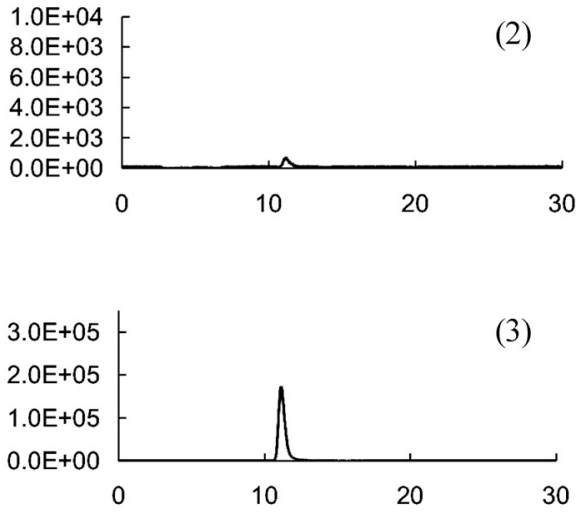

(4)

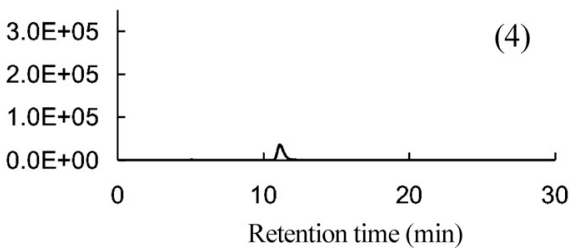

Fig. 1. IC-MS/MS chromatograms of standard solution at $0.1 \mathrm{ng} / \mathrm{mL}$ and a wine sample A: Standard solution (perchlorate: $0.1 \mathrm{ng} / \mathrm{mL}$, IS: $5.0 \mathrm{ng} / \mathrm{mL}$ )

B: Wine sample (IS: $5.0 \mathrm{ng} / \mathrm{mL}$ )

(1) $m / z 98.9 \rightarrow 83.1$ perchlorate primary transition

(2) $m / z 100.8 \rightarrow 84.9$ perchlorate secondary transition

(3) $m / z 106.8 \rightarrow 88.9$ IS primary transition

(4) $m / z 108.9 \rightarrow 91.1$ IS secondary transition

\section{2. 実態調査}

各試料中の過塩素酸塩濃度の測定結果を Table $2 \sim 7$ に 示す。また，Fig. 2 には試料ごとの過塩素酸塩濃度をグラ フにプロットして示した。
1) ワイン

28 試料すべての試料に $0.2 \sim 102.6 \mathrm{ng} / \mathrm{g}$ の過塩素酸塩 が含まれ, その平均值は $19.9 \mathrm{ng} / \mathrm{g}$, 中央值は $3.2 \mathrm{ng} / \mathrm{g}$ であった。多くの試料中の濃度は $10 \mathrm{ng} / \mathrm{g}$ 未満であった 
Table 2. Concentration of perchlorate in 28 wine samples

\begin{tabular}{cccc}
\hline \hline Sample No. Kinds of wine & Area of production & Concentration $(\mathrm{ng} / \mathrm{g})^{*}$ \\
\hline 1 & Red & Domestic & 0.7 \\
2 & Red & Domestic & 0.4 \\
3 & Red & France & 0.3 \\
4 & Red & France & 1.0 \\
5 & Red & Italy & 1.1 \\
6 & Red & USA & 1.6 \\
7 & Red & Australia & 3.4 \\
8 & Red & Chile & 8.2 \\
9 & Red & Chile & 5.9 \\
10 & Red & Chile & 13.0 \\
11 & Red & Chile & 10.7 \\
12 & Red & Chile & 56.9 \\
13 & Red & Spain & 11.8 \\
14 & Red & Germany & 10.6 \\
15 & White & Domestic & 0.3 \\
16 & White & Domestic & 0.3 \\
17 & White & France & 0.4 \\
18 & White & France & 0.2 \\
19 & White & Italy & 2.2 \\
20 & White & USA & 3.0 \\
21 & White & Australia & 1.6 \\
22 & White & Chile & 102.6 \\
23 & White & Chile & 86.6 \\
24 & White & Chile & 72.2 \\
25 & White & Chile & 97.9 \\
26 & White & Chile & 57.3 \\
27 & White & Spain & 3.7 \\
28 & White & Germany & 3.0 \\
\hline & & &
\end{tabular}

* Perchlorate anion level

Table 3. Concentration of perchlorate in 20 seafood samples

\begin{tabular}{|c|c|c|c|}
\hline Sample No. & Commodity & Area of production & Concentration $(\mathrm{ng} / \mathrm{g})^{* 1}$ \\
\hline 1 & Matsubara stingfish & USA & 0.9 \\
\hline 2 & Walleye pollack & USA & 0.9 \\
\hline 3 & Sablefish & USA & 4.1 \\
\hline 4 & Peeled shrimp & India & NQ $(0.35)^{* 2}$ \\
\hline 5 & Squid tube & China & 2.9 \\
\hline 6 & Grilled mackerel & China & ND*3 \\
\hline 7 & Herring & Norway & NQ (0.64) \\
\hline 8 & Seed flounder & USA & 0.8 \\
\hline 9 & Snow crab leg-meat & China & $\mathrm{NQ}(0.32)$ \\
\hline 10 & Nile perch & Tanzania & $\mathrm{NQ}(0.37)$ \\
\hline 11 & Japanese smelt & China & 1.5 \\
\hline 12 & Salmon & Chile & $\mathrm{NQ}(0.54)$ \\
\hline 13 & Split and dried saurel & Holland & NQ (0.52) \\
\hline 14 & Atka mackerel & USA & NQ (0.37) \\
\hline 15 & Dried roundnose flounder & Scotland & 5.0 \\
\hline 16 & Peeled shrimp & Myanmar & 1.3 \\
\hline 17 & Black tiger prawn & Indonesia & 1.8 \\
\hline 18 & Prawn & India & 0.9 \\
\hline 19 & Whiteleg shrimp & Indonesia & 71.6 \\
\hline 20 & Angler & China & 4.8 \\
\hline
\end{tabular}


Table 4. Concentration of perchlorate in 10 polished rice samples

\begin{tabular}{clcc}
\hline \hline Sample No. & Product name & Area of production & Concentration $(\mathrm{ng} / \mathrm{g})^{* 1}$ \\
\hline 1 & Nanatsuboshi & $\mathrm{a}$ & $\mathrm{ND}^{* 2}$ \\
2 & Hitomebore & $\mathrm{b}$ & $\mathrm{ND}$ \\
3 & Akita-komachi & $\mathrm{c}$ & $\mathrm{NQ}(0.70)^{* 3}$ \\
4 & Fusaotome & $\mathrm{d}$ & $\mathrm{NQ}(0.63)$ \\
5 & Koshi-ibuki & $\mathrm{e}$ & $\mathrm{NQ}(0.73)$ \\
6 & Milkyqueen & $\mathrm{f}$ & $\mathrm{NQ}(0.58)$ \\
7 & Koshihikari & $\mathrm{g}$ & $\mathrm{ND}$ \\
8 & Koshihikari & $\mathrm{h}$ & $\mathrm{ND}$ \\
9 & Koshihikari & $\mathrm{i}$ & $\mathrm{ND}$ \\
10 & Yumeshizuku & $\mathrm{j}$ & $\mathrm{ND}$ \\
\hline
\end{tabular}

*1 Perchlorate anion level

*2 $0.3 \mathrm{ng} / \mathrm{g} \leq \mathrm{NQ}<1.0 \mathrm{ng} / \mathrm{g}$

$* 3 \mathrm{ND}<0.3 \mathrm{ng} / \mathrm{g}$

Table 5. Concentration of perchlorate in 30 milk samples

\begin{tabular}{|c|c|c|c|}
\hline Sample No. & Type of milk & Manufacturing company & Concentration $(\mathrm{ng} / \mathrm{g})^{* 1}$ \\
\hline 1 & Whole milk & $\mathrm{A}$ & 6.5 \\
\hline 2 & Whole milk & $\mathrm{A}$ & 3.2 \\
\hline 3 & Milk drink & $\mathrm{A}$ & 5.7 \\
\hline 4 & Milk drink & $\mathrm{A}$ & 7.7 \\
\hline 5 & Milk drink & $\mathrm{A}$ & 5.3 \\
\hline 6 & Whole milk & $\mathrm{A}$ & 5.6 \\
\hline 7 & Whole milk & $\mathrm{B}$ & 2.0 \\
\hline 8 & Whole milk & $\mathrm{C}$ & 4.1 \\
\hline 9 & Whole milk & $\mathrm{C}$ & 3.7 \\
\hline 10 & Whole milk & $\mathrm{C}$ & 6.9 \\
\hline 11 & Whole milk & $\mathrm{C}$ & 4.5 \\
\hline 12 & Whole milk & $\mathrm{C}$ & 5.0 \\
\hline 13 & Composition modified milk*2 & $\mathrm{C}$ & 8.4 \\
\hline 14 & Low-fat milk & $\mathrm{C}$ & 5.6 \\
\hline 15 & Low-fat milk & $\mathrm{C}$ & 6.7 \\
\hline 16 & Processed milk & $\mathrm{C}$ & 7.0 \\
\hline 17 & Whole milk & $\mathrm{D}$ & 8.4 \\
\hline 18 & Low-fat milk & $\mathrm{D}$ & 7.6 \\
\hline 19 & Whole milk & $\mathrm{E}$ & 6.6 \\
\hline 20 & Whole milk & $\mathrm{E}$ & 2.7 \\
\hline 21 & Whole milk & $\mathrm{F}$ & 6.0 \\
\hline 22 & Whole milk & $\mathrm{F}$ & 6.1 \\
\hline 23 & Whole milk & G & 8.0 \\
\hline 24 & Whole milk & $\mathrm{H}$ & 6.7 \\
\hline 25 & Whole milk & I & 7.7 \\
\hline 26 & Whole milk & I & 10.6 \\
\hline 27 & Whole milk & $\mathrm{J}$ & 6.6 \\
\hline 28 & Milk drink & $\mathrm{J}$ & 4.2 \\
\hline 29 & Whole milk & $\mathrm{K}$ & 7.0 \\
\hline 30 & Milk drink & $\mathrm{K}$ & 7.9 \\
\hline
\end{tabular}

*1 Perchlorate anion level

*2 Milk fat that was adjusted to $2-3 \%$ 
Table 6. Concentration of perchlorate in 10 powdered milk samples

\begin{tabular}{|c|c|c|c|c|}
\hline \multirow{2}{*}{ Sample No. } & \multirow{2}{*}{ Type of powdered milk } & \multirow{2}{*}{ Manufacturing company } & \multicolumn{2}{|c|}{ Concentration $(\mathrm{ng} / \mathrm{g})^{* 1}$} \\
\hline & & & In powder & In prepared \\
\hline 1 & Early infant formula & K & 3.2 & 0.4 \\
\hline 2 & Follow-on and toddler formula & $\mathrm{K}$ & 11.4 & 1.5 \\
\hline 3 & Early infant formula & $\mathrm{D}$ & 7.4 & 1.0 \\
\hline 4 & Follow-on and toddler formula & $\mathrm{D}$ & 2.5 & 0.3 \\
\hline 5 & Early infant formula & $\mathrm{L}$ & 6.3 & 0.8 \\
\hline 6 & Follow-on and toddler formula & $\mathrm{L}$ & 35.3 & 4.9 \\
\hline 7 & Early infant formula & M & 4.1 & 0.5 \\
\hline 8 & Follow-on and toddler formula & $\mathrm{M}$ & 13.9 & 1.9 \\
\hline 9 & Early infant formula & $\mathrm{N}$ & 9.0 & 1.2 \\
\hline 10 & Modified milk powder & $\mathrm{D}$ & 7.6 & —2 \\
\hline
\end{tabular}

*1 Perchlorate anion level

${ }^{*}$ Not reduced

Table 7. Concentration of perchlorate in 10 yogurt samples

\begin{tabular}{clcr}
\hline \hline Sample No. & \multicolumn{1}{c}{ Major additives } & Manufacturing company $^{\text {Concentration }(\mathrm{ng} / \mathrm{g})^{* 1}}$ \\
\hline 1 & Suger-agar & $\mathrm{E}$ & 5.5 \\
2 & Suger-agar-fresh cream & $\mathrm{O}$ & 10.9 \\
3 & Suger-coconut oil & $\mathrm{D}$ & 7.7 \\
4 & Suger-gelatine & $\mathrm{P}$ & 9.0 \\
5 & Suger & $\mathrm{Q}$ & 2.1 \\
6 & Suger-sweetener & $\mathrm{K}$ & 6.0 \\
7 & Suger & $\mathrm{K}$ & 7.2 \\
8 & Suger-fructose-agar-gelatine-cream & $\mathrm{C}$ & 5.4 \\
9 & Suger-fructose-sweetener-agar-gelatine-cream & $\mathrm{C}$ & 4.9 \\
10 & Plain & $\mathrm{A}$ & 6.9 \\
\hline
\end{tabular}

*1 Perchlorate anion level

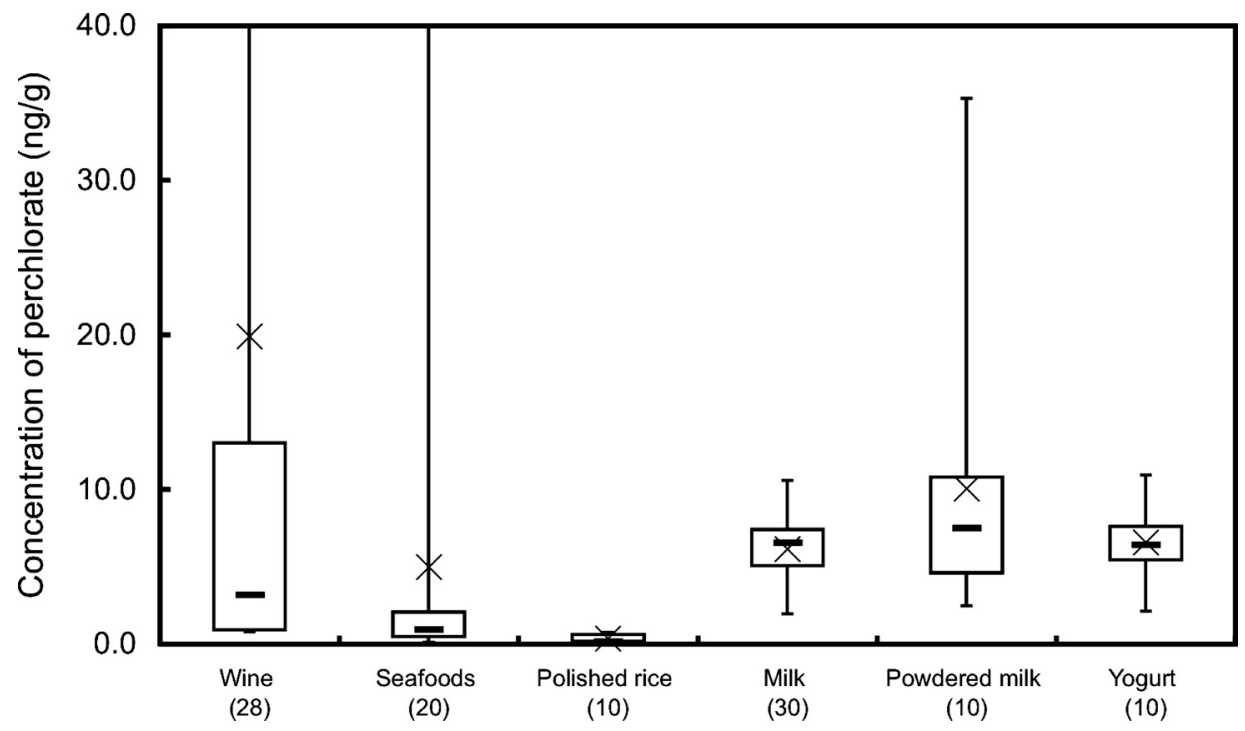

Fig. 2. Distribution of perchlorate concentrations in 6 kinds of foods

$H$ : concentration range, $\times$ : mean, $-:$ median, $\square: 25$ and 75 percentile ranges,

( ) : number of samples

が，チリ産の赤ワイン 3 試料および白ワイン 5 試料，ス ペインおよびドイツ産の赤ワイン各 1 試料の計 10 試料に ついては $10 \mathrm{ng} / \mathrm{g}$ を超えていた. チリでは土壤中に過塩 素酸塩が含まれていることが知られており*1, チリ産ワイ ン中の過塩素酸塩の濃度が高いのは，このことが原因と考 えられる。 また, Aribi ら6)により報告されたワイン 77 試
料中の過塩素酸塩濃度は，0.01〜 $50.3 \mathrm{mg} / \mathrm{L}$ の範囲であ り, それらの平均值が $5.0 \mathrm{mg} / \mathrm{L}$ であった。 また, 含有量 が高いワインの産地はチリを中心としており, 本調査に よっても同様の傾向が確認できたと言える.

\section{2) 魚介類}

輸入魚介類 20 試料中 12 試料に $0.8 \sim 71.6 \mathrm{ng} / \mathrm{g}$ の範囲 
で過塩素酸塩が含まれ, それらの平均は $5.0 \mathrm{ng} / \mathrm{g}$, 中央 值は $0.9 \mathrm{ng} / \mathrm{g}$ であった。過塩素酸塩濃度が $10 \mathrm{ng} / \mathrm{g}$ を超 えた試料はインドネシア産のエビ $(71.6 \mathrm{ng} / \mathrm{g})$ の 1 試料の みであり, 他の 11 試料は $5 \mathrm{ng} / \mathrm{g}$ 以下であった。 その他 の試料については, LOD $(0.2 \mathrm{ng} / \mathrm{g})$ 以下が 1 試料, LOQ $(0.8 \mathrm{ng} / \mathrm{g})$ 以下の濃度が検出された試料が 7 試料あった。 FDA が 2004 および 2005 年に実施した過塩素酸塩濃度 の調査*2では, 魚介類 23 試料中, LOD (1.00 ng/g) 以下 が 17 試料, LOQ (3.00 ng/g) 以下が 3 試料, 残りの 3 試 料から 23.2, 23.5 および $50.5 \mathrm{ng} / \mathrm{g}$ の過塩素酸塩が検出 されている.この 3 試料はいずれもエビで, 産地はそれ ぞれインド, タイ, ベトナムと異なっていた。本調査結果 では，エビから高濃度の過塩素酸塩を検出したことは FDA の結果とも類似している. 他の試料の過塩素酸塩濃 度は, 魚種が多岐にわたっているが， 1 例ずっで，すべて 輸入品なので国産品を含めた産地などを増やして調査する 必要があるあのと思われる。

\section{3) 精米}

10 試料中 LOD (0.3 ng/g) 以下の試料が 6 試料, LOQ $(1.0 \mathrm{ng} / \mathrm{g})$ 以下の濃度で検出された試料が 4 試料で, LOQ 以上の濃度の過塩素酸塩を含む試料はなかった。こ れらの結果はFDA の調査結果*2 とも一致している.

\section{4) 乳}

国産品である 30 試料すべてに過塩素酸塩が $2.0 \sim 10.6$ $\mathrm{ng} / \mathrm{g}$ の範囲で含まれ, それらの平均は $6.1 \mathrm{ng} / \mathrm{g}$, 中央值 は $6.6 \mathrm{ng} / \mathrm{g}$ であった. Dyke ら ${ }^{9)}$ は,アメリカ産牛乳 104 試料の調査結果 $(1.5 \sim 11.3 \mu \mathrm{g} / \mathrm{L}$, 平均值 $5.74 \mu \mathrm{g} / \mathrm{L}$, 中央 值 $5.56 \mu \mathrm{g} / \mathrm{L})$ と日本産牛乳 54 試料の調査結果（5.45〜 $16.40 \mu \mathrm{g} / \mathrm{L}$, 平均值 $9.39 \mu \mathrm{g} / \mathrm{L}$, 中央值 $9.34 \mu \mathrm{g} / \mathrm{L})$ を比 較し, 日本産の牛乳にはより高濃度の過塩素酸塩が含まれ る傾向にあると報告している。 FDA は 2004 および 2005 年の調查結果*2 として, 125 試料中 LOD $(1.00 \mathrm{ng} / \mathrm{mL})$ 以下が 3 試料, $\mathrm{LOQ}(3.00 \mathrm{ng} / \mathrm{mL})$ 以下が 2 試料, 他の 試料中の過塩素酸塩濃度は $3.16 \sim 11.3 \mathrm{ng} / \mathrm{mL}$ と報告し ており，この結果は本調査とも一致していると言える.

\section{5) 粉乳}

乳同様, 国産品である 10 試料すべてに過塩素酸塩が $2.5 \sim 35.3 \mathrm{ng} / \mathrm{g}$ の範囲で含まれ, その平均值は $10.1 \mathrm{ng} /$ $\mathrm{g}$, 中央值は $7.5 \mathrm{ng} / \mathrm{g}$ であった。 これらは粉乳の単位重 量当たりの濃度である. 実際に飲む乳としての濃度に換算 すると, $0.3 \sim 4.9 \mathrm{ng} / \mathrm{g}$ (平均值 $1.4 \mathrm{ng} / \mathrm{g}$ ) となり, 牛乳 より低濃度であった. No. 10 の試料はコーヒーなどに加 えることを用途とする粉乳であり, 乳幼児の粉乳より少な い量をコーヒーなどに溶解するのでこちらむ特に高い值と はいえない

\section{6) ヨーグルト}

10 試料すべてに過塩素酸塩が $2.1 \sim 10.9 \mathrm{ng} / \mathrm{g}$ の範囲で 含まれ, その平均值は $6.6 \mathrm{ng} / \mathrm{g}$, 中央值は $6.4 \mathrm{ng} / \mathrm{g}$ で あった。

FDA の 2005 および 2006 年の調査報告*3には, 粉乳
およびヨーグルトが含まれており, 粉乳 8 試料中の過塩

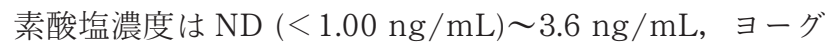
ルトは $1.7 〜 10.5 \mathrm{ng} / \mathrm{g}$ と報告されている. FDA は 4 つ の異なる地域の都市からマーケットバスケット方式で試料 を集め，各都市ごとにトータルダイエットスタディのデー 夕を求めているので，これらの值を各都市における平均的 な濃度と考えると, 本調査結果と比較して特に異なるとは 考えられない.

これまでに報告されている調査結果と本調査の結果を俯 瞰的に比較すると, ワインおよび魚介類試料中に高濃度の 過塩素酸塩を含む試料が数点認められたが, 試料別の過塩 素酸塩含有量平均值には，大きな差は認められなかった。

\section{ま と め}

日本で流通する食品の過塩素酸塩の含有量を調査するた め，既報5)で報告した葉菜類抢よび飲料水に引き続き， ワ イン, 魚介類, 精米, 乳, 粉乳およびヨーグルトについて 調査を行った。その結果，チリ産を中心とするワイン中に 比較的高濃度の過塩素酸塩を含む試料が認められたが，そ の他の食品中の濃度は，ほほ $10 \mathrm{ng} / \mathrm{g}$ 以下であった。本 調査の結果は米国での調査結果ともよく一致しており，わ が国で流通する食品を摂食することで, 過塩素酸塩による 健康被害を生じる可能性は低いと考えられる。しかし，産 地拉よび調査対象の食品を拡大し，さらに混入する原因を 調査するなど，わが国の食品中の過塩素酸塩の含有実態を 把握していく必要があるあのと考えられる.

\section{文献}

1) Blount, B. C., Pirkle, J. L., Osterloh, J. D., ValentinBlasini, L., Caldwell, K. L. Urinary perchlorate and thyroid hormone levels in adolescent and adult men and women living in the United States. Environmental Health Perspective, 114, 1865-1871 (2006).

2) Martinelango, P. K., Tian, K., Dasgupta, P. K. Perchlorate in seawater bioconcentration of iodide and perchlorate by various seaweed species. Anal. Chim. Acta, 567, 100-107 (2006).

3) Jackson, W. A., Joseph, P., Laxman, P., Tan, K., Smith, P. N., Yu, L., Anderson, T. A. Perchlorate accumulation in forage and edible vegetation. J. Agric. Food Chem., 53, 369-373 (2005).

4) Sanchez, C. A., Krieger, R. I., Khandaker, N., Moore, R. C., Holts, K. C., Neidel, L. L. Accumulation and perchlorate exposure potential of lettuce produced in the lower colorado river region. J. Agric. Food Chem., 53, 5479-5486 (2005).

5) Takatsuki, S., Watanabe, T., Sakai, T., Matsuda, R., Maitani, T. Surveillance of perchlorate level in leafy vegetables and bottled water. Shokuhin Eiseigaku Zasshi (J. Food Hyg. Soc. Japan), 50, 184-189 (2009).

6) Aribi, H. E., Blanc, Y. J. C. L., Antonsen, S., Sakuma, T. Analysis of perchlorate in foods and beverages by ion chromatography coupled with tandem mass spec- 
trometry (IC-ESI-MS / MS), Anal. Chim. Acta, 567, 3947 (2006).

7) Krynitsky, A. J., Niemann, R. A., Nortrup, D. A. Determination of perchlorate anion in foods by ion chromatography-tandem mass spectrometry. Anal. Chem., 76, 5518-5522 (2004).

8) Krynitsky, A. J., Niemann, R. A., Williams, A. D., Hopper, M. L., Streamlined sample preparation proce- dure for determination of perchlorate anion in food by ion chromatography-tandem mass spectrometry. Anal. Chim. Acta, 567, 94-99 (2006).

9) Dyke, J. V., Ito, K., Obitsu, T., Hisamatsu, Y., Dasgupta, P. K., Blount, B. C. Perchlorate in dairy milk. Comparison of Japan versus the United States. Environ. Sci. Technol., 41, 88-92 (2007). 